\title{
Molecular Orientation of Intercalants Stabilized in the Interlayer Space of Layered Ceramics: 1-D Electron Density Simulation
}

\author{
Jae-Hun Yang, Yi-Rong Pei, Huiyan Piao, Ajayan Vinu*, and Jin-Ho Choy ${ }^{\dagger}$ \\ Center for Intelligent Nano-Bio Materials (CINBM), Department of Chemistry and Nano Science, \\ Ewha Womans University, Seoul 03760, Korea \\ *Future Industries Institute, University of South Australia, Mawson Lakes 5095, Adelaide, Australia
}

(Received July 11, 2016; Revised July 18, 2016; Accepted July 18, 2016)

\begin{abstract}
In this review, an attempt is made to calculate one-dimensional (1-D) electron density profiles from experimentally determined (00l) XRD intensities and possible structural models as well in an effort to understand the collective intracrystalline structures of intercalant molecules of two-dimensional (2-D) nanohybrids with heterostructures. 2-D ceramics, including layered metal oxides and clays, have received much attention due to their potential applicability as catalysts, electrodes, stabilizing agents, and drug delivery systems. 2-D nanohybrids based on such layered ceramics with various heterostructures have been realized through intercalation reactions. In general, the physico-chemical properties of such 2-D nanohybrids are strongly correlated with their heterostructures, but it is not easy to solve the crystal structures due to their low crystallinity and high anisotropic nature. However, the powder X-ray diffraction (XRD) analysis method is thought to be the most powerful means of understanding the interlayer structures of intercalant molecules. If a proper number of well-developed $(00 l)$ XRD peaks are available for such 2-D nanohybrids, the 1-D electron density along the crystallographic $c$-axis can be calculated via a Fourier transform analysis to obtain structural information about the orientations and arrangements of guest species in the interlayer space.
\end{abstract}

Key words : Layered ceramics, Clays, Intercalation, 2-D nanohybrids, 1-D Electron density simulation

\section{Introduction}

$\mathrm{L}$ ayered ceramic materials such as cationic clays, anionic clays such as layered double hydroxides (LDHs), layered metal oxides, layered metal chalcogenides, layered zirconium phosphates and carbonaceous layered compounds can be transformed into novel heterostructured materials through an intercalation reaction. ${ }^{1-7)}$ Intercalation is defined as a chemical process in which guest species are reversibly inserted into the interlayer gallery space of layered hosts to form new 2-D heterostructured materials without any structural reconstruction. $^{8-13)}$ As widely studied, guest species including atoms, molecules, clusters and their charged species, regardless of whether they are inorganic or organic or bio species, have been successfully intercalated into layered ceramic materials to form various inorganic/ceramic, organic/ceramic and bio/ceramic 2 -D nanohybrids with heterostructures. More recently, such hybrids have attracted considerable attention due to their multiplex potential for application in various fields such as energy and the environment, and in medical healthcare industries. ${ }^{14-21)}$

In general, the physico-chemical properties of 2-D nanohybrids are strongly related to their heterostructures; there-

\footnotetext{
${ }^{\dagger}$ Corresponding author: Jin-Ho Choy

E-mail : jhchoy@ewha.ac.kr

Tel : +82-2-3277-4135 Fax : +82-2-3277-4340
}

fore, X-ray diffraction (XRD) analyses are required to solve their crystal structures in order to predict their structureproperty relationships. However, when they are poor in terms of crystallinity due to their porous and/or amorphous nature resulting from lattice strains upon intercalation, such as structural defects and stacking faults, their structures can be analyzed not only by conventional XRD and small-angle X-ray scattering analyses but also by X-ray absorption spectroscopy (XAS), nuclear magnetic resonance spectroscopy (NMR), molecular dynamics simulations, and electron microscopic tools such as SEM and TEM. ${ }^{622-26)}$

To characterize such intercalative nanohybrids, powder $\mathrm{XRD}$ is the most common means of solving their structures along with one-dimensional (1-D) electron density map calculations, as well-ordered intercalative nanohybrids generally show a series of well-ordered (00l) XRD peaks corresponding to the basal spacing $(d)$, of which the values increase upon intercalation. ${ }^{27)}$ If a large number of $(00 l)$ XRD peaks were available for an intercalated nanohybrid, its 1-D electron density map along the crystallographic $c$ axis could be determined via the Fourier transform of the calculated structure factor, which reflects the intracrystalline structure, such as the molecular orientations and arrangements, of the guest species in the interlayer space.

In this review, X-ray characterizations of intercalative nanohybrids are highlighted with some examples of layered hosts, such as metal oxides, cationic clays and LDHs as 
reported thus far, on the basis of the powder X-ray diffraction method with the 1-D electron density mapping technique. In addition, an attempt is also made to discuss experimental results with theoretical principles in detail in order to assist with an understanding of the structure-property relationships of such intercalative nanohybrids.

\section{Structures of Layered Ceramic Materials}

To predict the physico-chemical properties of 2-D nanohybrids with a heterostructure, their crystal structures should be well defined immediately after the synthesis process.

As well-known ceramic raw materials, smectites such as montmorillonite (MMT), saponite and hectorite are typical layered compounds belonging to cationic clays of the $2: 1$ (the ratio of tetrahedral sheets to octahedral sheets) type. According to the crystal structure of smectite, infinite twodimensional sheets are sequentially stacked along the $c$-axis to form a multilayer structure, where each sheet consists of a $\mathrm{AlO}_{6}$ - or $\mathrm{MgO}_{6}$-octahedral $\left(\mathrm{O}_{\mathrm{h}}\right)$ layer covalently sandwiched between two $\mathrm{SiO}_{4}$-tetrahedral $\left(\mathrm{T}_{\mathrm{d}}\right.$ ) layers (Fig. 1(a)). ${ }^{6,23,27)}$ If $\mathrm{Si}^{4+}$ in the tetrahedral sheets and/or $\mathrm{Al}^{3+}$ or $\mathrm{Mg}^{2+}$ in the octahedral sheets are partially substituted by lower valent $\mathrm{Al}^{3+}$ or $\mathrm{Fe}^{3+}$, and/or $\mathrm{Mg}^{2+}$ or $\mathrm{Fe}^{2+}$ or $\mathrm{Li}^{+}$, respectively, a negative layer charge can be generated. In order to compensate for the generated layer charge, interlayer cations such as hydrated $\mathrm{Na}^{+}$and $\mathrm{Ca}^{2+}$ ions must be stabilized between the two-dimensional clay lattice. Such interlayer cations are, however, readily exchangeable with other cationic species, regardless of whether they are inorganic, organic, or bioactive molecules.

On the other hand, anionic clays, known as LDHs with anion-exchange properties, are often denominated as hydro- talcite-like materials due to similarities in terms of the crystal structure and layer charge of the hydrotalcite mineral $\left(\mathrm{Mg}_{6} \mathrm{Al}_{2}(\mathrm{OH})_{16} \mathrm{CO}_{3} \cdot 4 \mathrm{H}_{2} \mathrm{O}\right)$ in nature. The chemical formula of $\mathrm{LDH}$ is described as $\left[\mathrm{M}^{2+}{ }_{1-\mathrm{x}} \mathrm{M}^{3+}{ }_{\mathrm{x}}(\mathrm{OH})_{2}\right]^{\mathrm{x}+}\left(\mathrm{A}^{\mathrm{m}-}\right)_{\mathrm{x} / \mathrm{m}} \mathrm{nH}_{2} \mathrm{O}$, where $\mathrm{M}^{2+}$ is a divalent metal, $\mathrm{M}^{3+}$ is a trivalent metal, and $\mathrm{A}^{\mathrm{m}-}$ is an interlayer anion. ${ }^{6,722,27)}$ To understand the crystal structure of $\mathrm{LDH}$ in detail, it is necessary to explain the basic structure of brucite, $\mathrm{Mg}(\mathrm{OH})_{2}$, in which divalent $\mathrm{Mg}^{2+}$ ions are coordinated with six hydroxo ligands to form octahedra, which are then bound to one another by sharing edges to form an infinite sheet. In brucite, these sheets are stacked on top of each other to build up the layered structure through hydrogen bonding. In the LDH structure, however, divalent cations such as $\mathrm{Mg}^{2+}, \mathrm{Zn}^{2+}, \mathrm{Ni}^{2+}, \mathrm{Ca}^{2+}$, and $\mathrm{Fe}^{2+}$ are partially substituted by higher valent cations such as $\mathrm{Al}^{3+}$, $\mathrm{Cr}^{3+}$ and $\mathrm{Fe}^{3+}$, resulting in a positive layer charge in the lattices. To compensate for the positive layer charge, solvated anionic species are simultaneously located in the interlayer space of the $\mathrm{LDH}$ lattice, which can be exchanged with other anionic molecules, as shown in Fig. 1(d). ${ }^{28)}$

Among the various types of layered metal oxides, the crystal structures of layered titanates ${ }^{11,14,29)}$ and Bi-based cuprate high- $\mathrm{T}_{\mathrm{c}}$ superconductors $\mathrm{s}^{30,31)}$ are briefly introduced in this section. A series of alkali metal titanates with a lepidocrocite (g-FeOOH)-related structure with the general formula of $\mathrm{A}_{\mathrm{x}} \mathrm{Ti}_{2-\mathrm{y}} \mathrm{M}_{\mathrm{y}} \mathrm{O}_{\mathrm{z}}(\mathrm{A}=\mathrm{Na}, \mathrm{K}, \mathrm{Cs}, \mathrm{Rb}$ and $\mathrm{M}=\mathrm{Mg}, \mathrm{Co}, \mathrm{Ni}$, $\mathrm{Fe}, \mathrm{Ti}, \mathrm{Nb}$, etc.) has a layer structure built up by sharing the edges and corners of $\mathrm{TiO}_{6} / \mathrm{MO}_{6}$ octahedra, as shown in Fig. 1(b). The alkali metal ions located between the layers are exchangeable with other cations such as protons, other metal ions or organic cations. Their protonic forms are known to be expandable and, in consequence, easily exfoliated by intercalating bulky cationic molecules into metal (a)

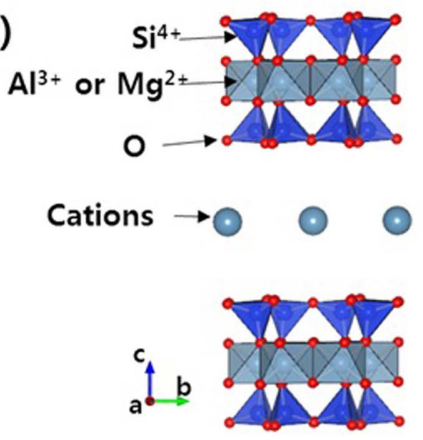

(d)

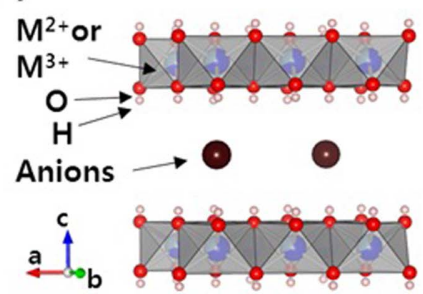

(b)

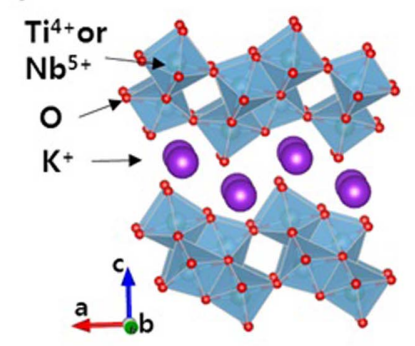

(e)

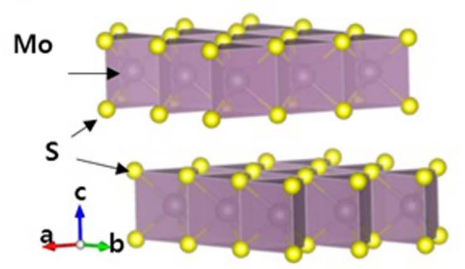

(c)

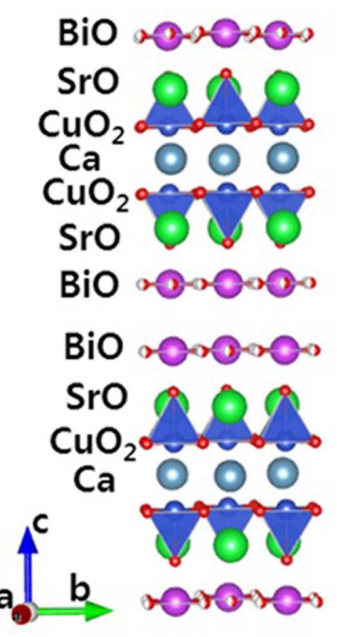

Fig. 1. Crystal structures of various layered materials; (a) montmorillonite, (b) $\mathrm{KTiNbO}_{5},(\mathrm{c}) \mathrm{Bi}_{2} \mathrm{Sr}_{2} \mathrm{CaCu}_{2} \mathrm{O}_{8}$, (d) $\mathrm{LDH} \mathrm{and}(\mathrm{e})$ $\mathrm{MoS}_{2}$. 
titanate nanosheets. $^{29,32-34)}$ These exfoliated layers can further be used as building blocks for preparing heterostructured nanohybrids based on the lattice engineering strategy.

Bismuth cuprate high- $\mathrm{T}_{\mathrm{c}}$ superconductors are also an example of a layered metal oxide, with the general formula of $\mathrm{Bi}_{2} \mathrm{Sr}_{2} \mathrm{Ca}_{\mathrm{n}-1} \mathrm{Cu}_{\mathrm{n}} \mathrm{O}_{\mathrm{y}}$; they are often denoted as $\mathrm{Bi2201}$, Bi2212 and Bi2223, where n equals 1, 2 or 3 in this case, respectively. ${ }^{30,31)}$ For example, a single sheet of Bi2212 is composed of $\mathrm{BiO}, \mathrm{SrO}, \mathrm{CuO}_{2}, \mathrm{Ca}, \mathrm{CuO}_{2}, \mathrm{SrO}$ and $\mathrm{BiO}$ layers, and the sheets are sequentially stacked on the top of each other to form a multilayered structure via weak van der Waals interaction, as demonstrated in Fig. 1(c). It is, therefore, not surprising that such layered Bi-based cuprates are also applicable as intercalative host materials.

Transition-metal dichalcogenide with the formula of $\mathrm{MX}_{2}$ is an another example of a layered material with a covalent bonding characteristic, where $\mathrm{M}$ is a transition-metal atom (e.g., Mo, W) and X is a chalcogen (S, Se, or Te). ${ }^{5,6)}$ In the $\mathrm{MX}_{2}$ structure, the transition-metal atom is covalently bonded with six chalcogen ligands to form a prismatic unit, and the prismatic units formed in this manner are bounded to one another by the sharing of edges to form an infinite sheet (X-M-X). Specifically, these layers consist of a hexagonal plane of transition-metal atoms sandwiched between two hexagonal chalcogen planes (Fig. 1(e) that are stacked on top of each other to form a lamellar structure via weak Van der Waals interaction.

\section{Computation and Examples of the 1-D Electron Density of 2-D Nanohybrids with a Heterostructure}

$\mathrm{XRD}$ is a basic and powerful tool for characterizing the crystal structures of various solids. Therefore, the crystal structure of polycrystalline samples with good crystallinity can be solved via Rietveld refinement analysis (the entire XRD pattern fitting procedure to refine the structure) ${ }^{35-38)}$ However, 2-D nanohybrids with a heterostructure, such as intercalation compounds, are not good enough in terms of the X-ray crystallinity for a Rietveld refinement analysis, as their XRD peaks are often broad and asymmetric due to the lattice strain upon intercalation, such as structural defects and stacking faults. ${ }^{39-43)}$ Therefore, the collected XRD data are often not of a good quality; i.e., the $(h k l)$ peaks of $2-\mathrm{D}$ nanohybrids are poor as a whole, but a few sharp and strong (00l) peaks are frequently observed due to the effect of the preferred orientation of the 2-D particles. This is likely why only a few papers on Rietveld refinement have been reported thus far for layered materials intercalated with small organic and inorganic molecules, such as dimethylsulfoxide (DMSO), $\mathrm{Cl}^{-}$, and $\mathrm{CO}_{3}{ }^{2-44-47)}$

However, if a proper number of well-developed $(00 l)$ peaks were available for 2-D nanohybrids with a heterostructure, the structural arrangement of guest molecules in the interlayer space could be determined via Fourier transformation of the structure factors calculated from a series of $(00 l)$ peak intensities, resulting in a 1-D electron density map along the $c$-axis. ${ }^{12,42,48-53)}$ If there were various possible interlayer structural models for 2-D nanohybrids, one could determine a best fit structural model as physically and chemically meaningful for 2-D nanohybrids by comparing the calculated electron density profile with that evaluated from the experimental XRD pattern.

\subsection{Evaluation of 1-D Electron Density Map}

The 1-D electron density profile can be calculated with Eq. (1) from the positons and the intensities of a large number of $(\mathrm{OOl})$ XRD peaks for intercalative nanohybrids. ${ }^{54-58)}$

$$
\rho(z / c)=\frac{1}{c} \sum_{l=-\infty}^{\infty} F(00 l) e^{-i\left(\frac{2 \pi l z}{c}\right)}
$$

This equation for centrosymmetric structures can be transformed to the following one (Eq. (2)),

$$
\rho(z / c)=\frac{2}{c} \sum_{l=0}^{\infty} F(00 l) \cos \left(\frac{2 \pi l z}{c}\right)
$$

where $l, F(00 l), c$ and $z$ are the order of the $(00 l)$ diffraction peak, the structure factor, the unit cell parameter of the $c$ axis, and the atomic coordinate along the $z$-axis, respectively.

The structure factors corresponding to the expected structural model can also be calculated from the atomic scattering factors and positions in the structural model. The structural factor for centrosymmetric materials is calculated using the following equation (Eq. (3)),

$$
F_{c}(00 l)=\sum_{i=0}^{N} f_{i} \cos \left(2 \pi l \frac{z_{i}}{c}\right)
$$

where $f_{i}$ is the atomic scattering factor for each atom in the unit cell. For a practical calculation, the atomic scattering factors for x-ray as functions of the Bragg angle are represented by the following equation (Eq. (4)):

$$
f_{i}(\sin \theta / \lambda)=\left[c_{0}+\sum_{i=1}^{4} a_{i} \exp \left(-b_{i} \sin (\theta / \lambda)\right)\right] \exp \left(-\frac{B \sin ^{2} \theta}{\lambda^{2}}\right)(4)
$$

Here, the scattering factors of various neutral atoms and ions can be expressed as functions of nine coefficients for each element $\left(c_{0}, a_{1}-a_{4}, b_{1}-b_{4}\right)$ and $\sin \theta / l$, which are also found in the literature such as International Tables for Crystallography ${ }^{59-60)}$ The temperature factor, $B$, depends on the nature of the material. The typical range of the temperature factor $(B)$ is $\sim 0.5$ to $\sim 1 \AA^{2}$ for ceramic ionic crystals and intermetallic compounds, and from $\sim 1$ to $\sim 3 \AA^{2}$ for other inorganic and many coordination compounds, while this range extends from $\sim 3$ to $\sim 10 \AA^{2}$ or higher for organic and organometallic compounds and for solvents or other intercalated non-bonded molecules or atoms. ${ }^{61)}$ The atomic positions in the host layer can be obtained from the crystal structure of pristine layered materials before intercalation, and the initial interlayer structural model of guest species is 
established based on the Patterson diagram, the energyminimized chemical structure, and the results from other analyses, including NMR, XAFS and TEM analyses. ${ }^{31,51,52)}$

The experimentally observed structure factor, $F_{o}(00 l)$, can be derived from the intensities of the $(00 l)$ XRD peaks, which are obtained from the integrated peak areas. Here, $F_{o}(00 l)$ should be corrected with the Lorentz-Polarization (LP) factor, expressed as Eq. (5), as the absorption factor can generally be negligible when the intensities are calculated in Debye-Scherrer method. ${ }^{58,61)}$

$$
\left|F_{\mathrm{O}}(00 l)\right|=\sqrt{I(00 l) / \mathrm{LP}}
$$

where $\mathrm{LP}=\frac{1+\cos ^{2} 2 \theta}{\cos \theta \cdot \sin ^{2} \theta}$

The sign (phase) of the observed structure factor can be obtained from the calculated result from the predicted structural model, as they should be identical. With Eq. (2), the electron density profiles can be plotted from $z / c=-0.5$ to 0.5 for 2 -D nanohybrids.

From these computational processes, the observed 1-D electron density $\left(r_{0}\right)$ and the calculated one $\left(r_{c}\right)$ can be derived from the experimental XRD intensity (the integral peak area) and the predicted structural model, respectively. It then becomes possible to refine the reasonable orientation and arrangement of guest molecules in the interlayer by comparing these profiles. The reliability factor $(R)$ can be calculated with the following equation (Eq. (6)): ${ }^{57,62)}$

$$
R=\frac{\left(\Sigma|| F_{\mathrm{O}}(00 l)|-| F_{\mathrm{C}}(00 l)||\right)}{\Sigma\left|F_{\mathrm{O}}(00 l)\right|}
$$

\subsection{Examples of 1-D Electron Density Mapping for Inorganic/Inorganic $2 D$ Nanohybrids}

There are several reports on 1-D electron density mapping analyses of inorganic-inorganic 2-D nanohybrids such as the $\mathrm{HgBr}_{2}-\mathrm{Bi} 2212$ nanohybrid, ${ }^{48)}$ the AgI-Bi2212 nanohybrid, ${ }^{31,63)}$ and the $\mathrm{Ni}(\mathrm{OH})_{2}$-clay nanohybrid ${ }^{62)}$ which can be used to confirm the structural model of intercalated species established by NMR, TEM and XAFS analyses. For example, Choy et al. reported a inorganic/inorganic 2-D heterostructured nanohybrid, the AgI-intercalated Bi2212 nanohybrid $\left(\mathrm{Ag}_{1.17} \mathrm{I}_{1.54}\right.$-Bi2212), which demonstrated a superionic conductivity as well as a superconducting property. ${ }^{31,63)}$ From the EXAFS and Raman analyses, the structural model of the Ag-I sub-lattice was proposed considering the available interlayer space and the volume required for a two-dimensional array of $\mathrm{AgI}_{4}$ tetrahedra. The expanded basal spacing for Ag-I-intercalated Bi2212 compared to that of iodineintercalated Bi2212 demonstrated that an iodine double layer was present in the interlayer space and that the Ag-I sub-lattice should consist of a monolayer of $\mathrm{AgI}_{4}$ tetrahedra. Fig. 2 demonstrates the two most probable lattice types for $\mathrm{AgI}_{4}$ tetrahedra together with a schematic of the structural models upon intercalation, where one face (model A) or two edges (model B) are parallel to the $\mathrm{AB}$ plane of Bi2212. From the (Ag-I) bond distance determined by EXAFS analysis, the distance of I-I projected along the $c$-axis was estimated to be $3.75 \AA$ and $3.24 \AA$ for models A and B, respectively. As shown in Fig. 2(a), the height of the Ag-I layer in model A was consistent with the gallery height $(\sim 3.7 \AA)$ evaluated by subtracting the basal spacing of iodine-intercalated Bi2212 $(\sim 3.6 \AA)$

(a)
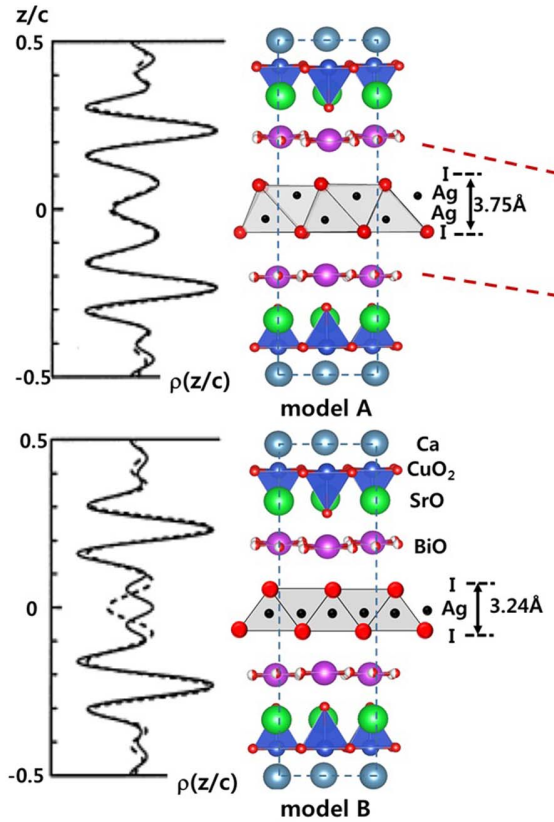

(c)

(b)
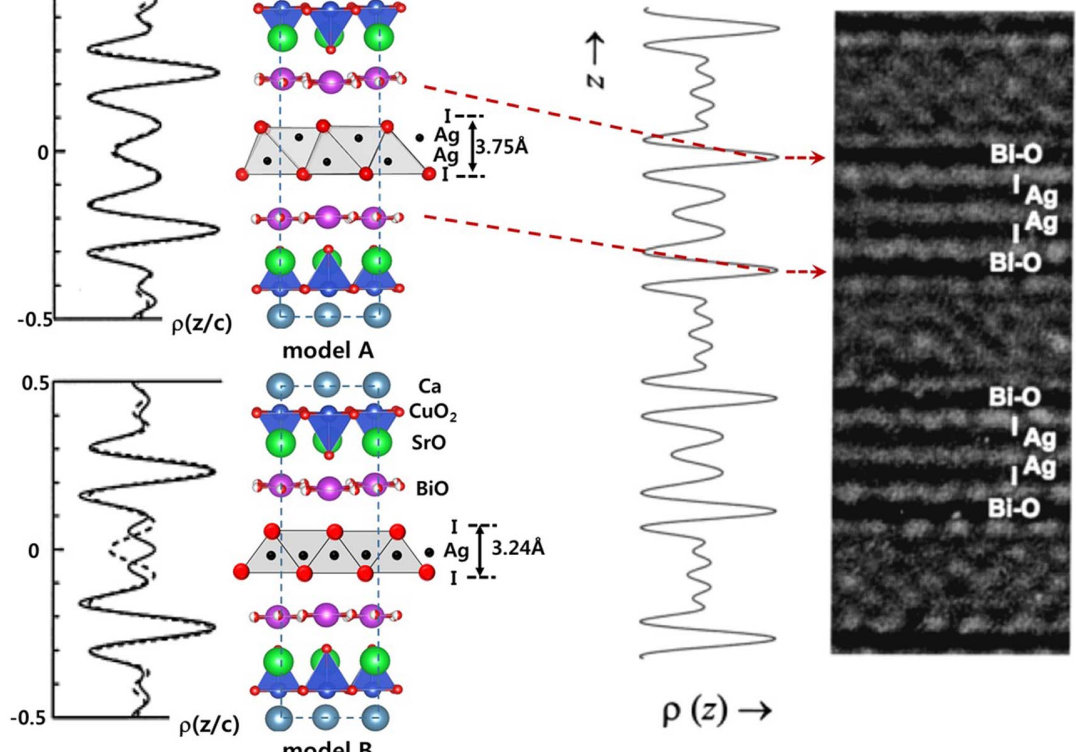

$\rho(z) \rightarrow$

Fig. 2. Proposed structures of (a) model A and (b) model B for the interlayer AgI lattice between Bi2212 layers, together with their corresponding 1-D electron density profiles, where the calculated values (solid line) are compared with the experimentally observed values (dotted line), and (c) HRTEM image of the $\mathrm{Ag}_{117} \mathrm{I}_{1.54}$-Bi2212 nanohybrid together with the 1-D electron density profile calculated based on the crystal structural model A. Reproduced and modified with permission from reference 63. Copyright 2000 American Chemical Society. 
from that of AgI-intercalated Bi2212 ( 7.3 $)$, indicating the suitability of model A. To confirm the reliability of this structure, 1-D electron density profiles along the $c$-axis were calculated in the following two ways. First, the c-axial electron density profiles $[r(z / c)]$ of AgI-Bi2212 can be obtained from the summation of structure factors as determined from the $(00 l)$ XRD peak intensities, where the magnitude of the structure factor, $\left|F_{00 l}\right|$, is the square root of the intensity corrected with the Lorentz polarization factor, as previous indicated in Eq. (5). The phase problem can be solved by assuming the conservation of intra-crystalline structure of host blocks during the intercalation process and by adopting the sign of calculated structure factor. Alternatively, $\left|F_{00 l}\right|$ and $r(z / c)$ can be calculated theoretically for the given intracrystalline structural models of the Ag-I sub-lattice between Bi2212 layers. The 1-D electron density profiles simulated on the basis of structural models A and B are compared in Fig. 2 (a) and (b), respectively, with that obtained from the experimental XRD data. As expected from the two different layer stacking sequences of $\cdots / \mathrm{BiO} / \mathrm{I} / \mathrm{Ag} / \mathrm{Ag} / \mathrm{I} / \mathrm{BiO} / \cdots$ $(\operatorname{model} \mathrm{A})$ and $\cdots / \mathrm{BiO} / \mathrm{I} / \mathrm{Ag} / \mathrm{I} / \mathrm{BiO} / \cdots($ model $\mathrm{B})$, the simulated patterns were found to be significantly distinguished in the region of the guest layer. The calculated $(z / c)$ profile with model A was in good agreement with the experimental case, which clarified the reliability of model A, where the reliability factor was determined to be less than 0.05 . In the $r(z / c)$ profiles based on XRD and on structural model A, the peaks at $z / c= \pm 0.08$ are attributed to the presence of $\mathrm{Ag}$ and I. Because both ions were located at highly adjacent positions on the $c$-axis, their individual contributions could not be separated but be observed as a single component, which provided an explicit explanation of the double-layered HRTEM pattern of the interlayer Ag-I lattice. As shown in Fig. 2(c), the dark spots in the magnified HRTEM image demonstrate good coincidence with peaks in the electron density profile evaluated from model A. This $\mathrm{Ag}_{1.17} \mathrm{I}_{1.54^{-}}$
Bi2212 nanohybrid exhibited fast ionic conductivity as high as $10^{-2}-10^{-1} \Omega^{-1} \mathrm{~cm}^{-1}$ in the range of $80-270^{\circ} \mathrm{C}$ and hightemperature superconductivity as well with a $\mathrm{T}_{\mathrm{C}}$ value of $67 \mathrm{~K}$, which is thought to be slightly lower than that of the pristine Bi2212 $(80 \mathrm{~K})$ due to the charge transfer between the host and the guest.

In the case of mercury bromide intercalated Bi2212, $\left(\mathrm{HgBr}_{2}\right)_{0.5} \mathrm{Bi}_{2} \mathrm{Sr}_{2} \mathrm{CaCu}_{2} \mathrm{O}_{\mathrm{y}}$, an unusual heterostructure consisting of a superconducting layer and an insulating one was suggested. ${ }^{48)}$ The interlayer structure of $\mathrm{HgBr}_{2}$ inbetween superconducting layers (Bi2212) was determined by the EXAFS fitting and XRD results. In order to confirm the reliability of this structure, 1-D electron density profiles along the $c$-axis obtained in two different ways were compared; one was calculated from the $(00 l) \mathrm{XRD}$ peak intensities for the well-oriented $\mathrm{HgBr}_{2}$-intercalated $\mathrm{Bi} 2212$ single crystal, and the other was calculated from the structure factor based on the present structural model, including the atomic positions and their occupation characteristics. According to Fig. 3, there was excellent accordance between the calculated and experimental 1-D electron density profiles, indicating the reliability of the present structural model in which linear $\mathrm{HgBr}_{2}$ molecules were present between the (Bi-O) double layers, as shown in Fig. 3. From this result, it was concluded that the $\mathrm{HgBr}_{2}$ linear molecule was tilted by $65^{\circ}$ with respect to the $c$-axis.

Uehara et al. reported another example of 1-D electron density mapping for inorganic-inorganic 2-D nanohybrids. ${ }^{62)}$ They were successful in intercalating $\mathrm{Ni}(\mathrm{OH})_{2}$ sheets into clay layers and suggested a model with a monolayer orientation of $\mathrm{Ni}(\mathrm{OH})_{2}$ simply by comparing the calculated and observed 1-D electron density profiles with a reasonable $R$ value of 0.10 . Argüelles et al. also suggested the positions of interlayer water molecules in vermiculite through 1-D electron density profile fitting. ${ }^{64)}$

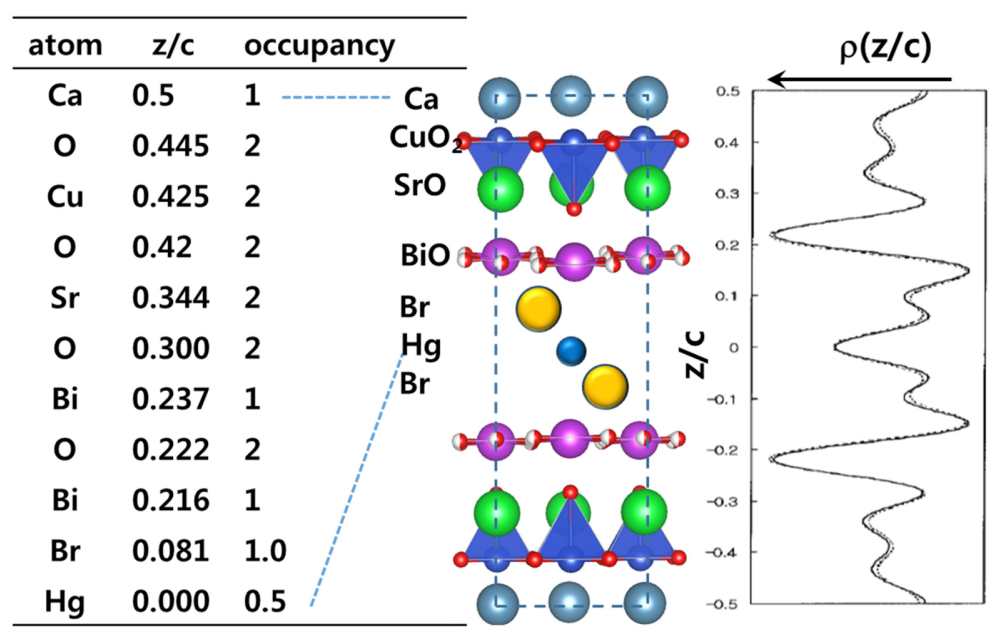

Fig. 3. 1-D electron density profiles along the $c$-axis of $\left(\mathrm{HgBr}_{2}\right)_{0.5} \mathrm{Bi}_{2} \mathrm{Sr}_{2} \mathrm{CaCu}_{2} \mathrm{O}_{\mathrm{y}}$ with its structural model and the atomic $z / c$ coordinates used. The dotted and solid lines represent 1-D electron density profile calculated from the intensities of the (00l) XRD peaks of $\mathrm{HgBr}_{2}$-intercalated $\mathrm{Bi} 2212$ nanohybrid and that calculated from the present structural model, respectively. Reproduced and modified with permission from reference 48. Copyright 1997 American Chemical Society. 


\subsection{Examples of 1-D Electron Density Mapping for Organic/Inorganic 2-D Nanohybrids}

There have been several reports of 1-D electron density mapping for organic-inorganic 2-D nanohybrids, for example layered ceramic materials intercalated with organic molecules, in an effort to determine the orientation and arrangement of organic molecules stabilized in the interlayer space. ${ }^{65-68)}$ For example, Marangoni et al. synthesized $\mathrm{Zn}_{2} \mathrm{Al}-\mathrm{LDH}$ nanohybrids intercalated with a series of blue dye molecules such as Evans blue (EB), Chicago sky blue (CB) and Niagara blue (NB) via a coprecipitation method, where interlayer structures of dye molecules were proposed by $1-\mathrm{D}$ electron density mapping. Due to the relatively large number of $(00 l)$ diffraction peaks (up to $7(00 l)$ peaks), they were able to suggest interlayer structures of those dye molecules projected on the c-axis via Fourier transform analysis. The 1-D electron density profiles for $\mathrm{CB}-\mathrm{Zn}_{2} \mathrm{Al}, \mathrm{EB}-\mathrm{Zn}_{2} \mathrm{Al}$ and $\mathrm{NB}-\mathrm{Zn}_{2} \mathrm{Al} \mathrm{LDH}$ nanohybrids are displayed in Fig. 4, where the integral intensities of XRD peaks were determined by the peak profile fitting method with the Fullprof program. ${ }^{69)}$ The 1-D electron density profiles for $\mathrm{CB}-\mathrm{Zn}_{2} \mathrm{Al}$ and $\mathrm{EB}-\mathrm{Zn}_{2} \mathrm{Al} \mathrm{LDH}$ nanohybrids were similar, while that $\mathrm{NB}-\mathrm{Zn}_{2} \mathrm{Al} \mathrm{LDH}$ nanohybrid was different from the others. For all the dye-LDH nanohybrids, the two strong peaks at $\mathrm{z}$ $=0 \AA$ and $20.4 \AA / 20.3 \AA / 23.4 \AA$ were attributed to the $\mathrm{LDH}$ layers, which contained metal cations, and the other lower electron density arose from the interlayer dye molecules. In all of the nanohybrids, relatively strong peaks at a distance of $4.0 \AA$ from the center of LDH layer were attributed to the sulfonate groups, as there were hydrogen bonding interactions between sulfonate groups and $\mathrm{OH}$ ones in $\mathrm{LDH}$ layers (-S-O $\cdots \mathrm{H}-\mathrm{O}-\mathrm{Metal})$. Hence, they proposed that the dye molecules such as $\mathrm{CB}$ and $\mathrm{EB}$ were intercalated into $\mathrm{LDH}$ layers with a tilting angle of $55-60^{\circ}$ with respect to the basal plane of $\mathrm{LDH}$ by considering the structural dimensions of dye molecules with a minimized level of steric energy. The methoxy groups in $\mathrm{CB}$ and $\mathrm{EB}$ provided medium electron density in the middle range of the interlayer of $\mathrm{LDH}$. However, 1-D electron density of $\mathrm{NB}-\mathrm{Zn}_{2} \mathrm{Al} \mathrm{LDH}$ nanohybrid was minimized at the center, which is different from those of other dye-LDH nanohybrids, indicating that NB molecules are most likely oriented with an arrangement of parallel bilayer inbetween the $\mathrm{LDH}$ layers due to the positions of sulfonate groups in NB; that is, all sulfonate groups in NB were not present at the opposite ends of the molecule, as in CB and $\mathrm{EB}$, but on the same side of the molecule. It is, therefore, highly expected to have such a bilayer arrangement resulting in a surface area of $\sim 17 \AA^{2}$ per unit charge, which is sufficiently small comparable to the equivalent area of the host lattice $\left(24.8 \AA^{2} \mathrm{e}^{-1}\right.$ for $\left.\mathrm{Zn}_{2} \mathrm{Al} \mathrm{LDH}\right)$.

As an another example of 1-D electron density mapping for an organic/inorganic 2-D nanohybrid, Fujita et al. proposed an appropriate molecular orientation of rhodamine 6G (R6G) in the interlayer space of Li-fluortaeniolite, ${ }^{66)}$ a smectite-type clay, by calculating 1-D electron density along the z-direction from ten well-ordered (00l) XRD peaks as well as from the possible model structures. Based on the expansion of basal spacing and the molecular dimension of R6G, they proposed two possible orientation models of R6G in the interlayer for Fourier transformation; one is a vertical model with a perpendicular monolayer orientation where the longest axis of xanthene ring in R6G is perpendicular to the basal plane of clay, and the other is a parallel model where the longest axis of xanthene ring is parallel to the basal plane, that is, R6G molecules are oriented with a bilayer stacking arrangement. The 1-D electron density profile calculated from the vertical model and the difference Fourier synthesis result are presented in Fig. 5 together with the proposed vertical model, including the positional parameters for R6G between the clay layers. As can be seen clearly in Fig. 5, the values from the difference Fourier synthesis along the c-axis are very small, indicating that the 1 -

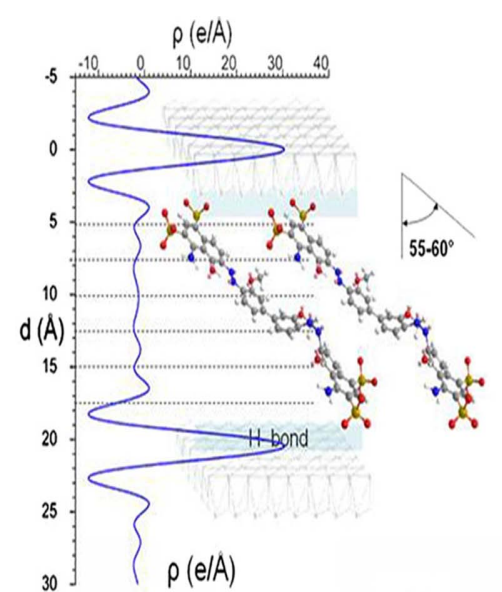

(a)

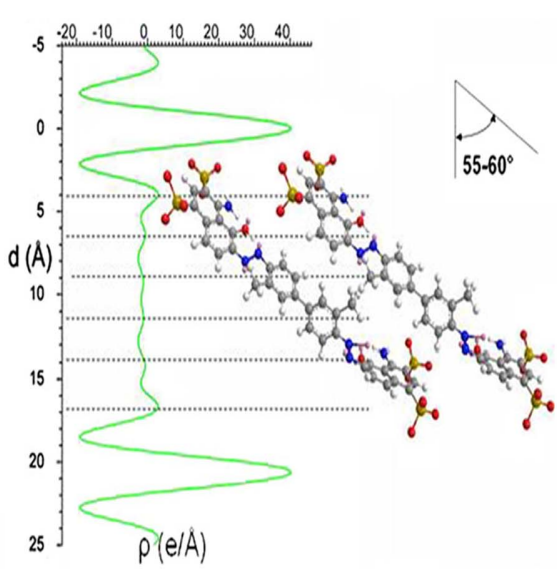

(b)

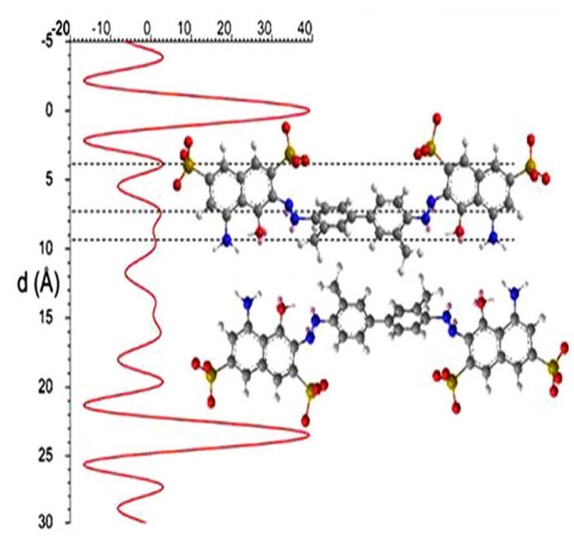

(c)

Fig. 4. 1-D electron density, $r(z)$ profiles projected along the c-axis for (a) $\mathrm{CB}-\mathrm{Zn}_{2} \mathrm{Al} \mathrm{LDH}$, (b) $\mathrm{EB}-\mathrm{Zn}_{2} \mathrm{Al} \mathrm{LDH}$ and (c) $\mathrm{NB}-\mathrm{Zn}_{2} \mathrm{Al}$ $\mathrm{LDH}$ nanohybrids and their corresponding structural models. Reproduced and modified with permission from reference 65. Copyright 2008 Elsevier Ltd. 
D electron density profile calculated from this vertical structural model is in excellent agreement with that calculated from the intensities of the $(00 l)$ XRD peaks. The R-factor for the vertical model was determined to be $\sim 0.01$, while that for the parallel model was $\sim 0.20$. Based on this 1-D electron density mapping analysis, they suggested the structural model of the R6G intercalated clay, where R6G was intercalated with a monolayer perpendicular orientation to the $a b$ plane of the clay layer, and the positively charged $N$ atoms of R6G were bonded to the negatively charged clay layers by strong electrostatic interactions.

A similar study of 1-D electron density mapping was also carried out on the PEO- $\mathrm{V}_{2} \mathrm{O}_{5}$ nanohybrid by Liu et al. ${ }^{55)}$ They successfully intercalated poly(ethylene oxide) (PEO) into a layered $\mathrm{V}_{2} \mathrm{O}_{5}$ xerogel simply by mixing an aqueous PEO solution with an aqueous $\mathrm{V}_{2} \mathrm{O}_{5}$ solution, after which they slowly evaporated the water molecules. According to the 1-D electron density mapping results, it was confirmed that the intercalated PEO chains were not in the form of a helical coil structure but with a zigzag conformation; that is, the PEO chains were fully extended and arranged horizontally with a bilayer conformation stacked on top of each other with respect to the (002) plane. The interaction between PEO and $\mathrm{V}_{2} \mathrm{O}_{5}$ in this organic-inorganic nanohybrid appeared to be the type of van der Waals and hydrogen bonding. As a similar example of organic/inorganic nanohybrid reported by Adams et al., tetrahydrofuran (THF) was intercalated into MMTs containing various cations such as $\mathrm{NH}^{4+}, \mathrm{Na}^{+}, \mathrm{Sr}^{2+}, \mathrm{Co}^{2+}, \mathrm{Ni}^{2+}$, and $\mathrm{Cu}^{2+}{ }^{67,68)}$ According to the 1-D electron density calculation, it was found that THF molecules were oriented perpendicularly to the basal plane of clay layers. Kanamaru et al. also proposed a parallel bi-layer orientation of 6-amino hexanoic acid in vermiculite through an 1-D electron density mapping analysis. ${ }^{56)}$ Bauer et al. also suggested the possible interlayer orientation of perylene dye, N,N'-di(phenyl-3,5disulfonic acid)perylene-3,4:9,10-tetracarboxyldiimide (PBITS) stabilized inbetween LDH layers based on 1-D electron density mapping analysis. ${ }^{70}$ Lerner et al. was also successful in preparing the bis(oxalato)borate anion (BOB) intercalated graphite in the presence of a solution containing BOB anion molecules in anhydrous hydrofluoric acid, and in mapping its 1-D electron density, and eventually in proposing the orientation of $\mathrm{BOB}$ anions in the basal plane of graphite. $^{71)}$ For porphyrin-LDH 2-D nanohybrids, ${ }^{72)}$ porphyrin molecules such as $\mathrm{Pd}(\mathrm{II})-5,10,15,20$-tetrakis(4carboxyphenyl) porphyrin (PdTPPC) and Zn-5,10,15,20tetrakis(4-sulfonateophenyl)porphyrin (ZnTPPS) were intercalated into $\mathrm{LDH}$ to form 2-D organic-inorganic nanohybrids. The interlayer orientation of porphyrin molecules was also confirmed to be perpendicular to the $\mathrm{LDH}$ layers on the basis of 1-D electron density mapping.

\subsection{Examples of 1-D Electron Density Mapping for Bio-organic/Inorganic 2-D Nanohybrids}

It has been reported that a large number of bio- and bioactive molecules, such as RNA, DNA, anti-oxidant molecules, and drug molecules, can be stabilized in layered materials such as clays and LDHs to form bio-inorganic 2-D nanohybrids. In this section, several examples of 1-D electron density mapping results of drug-LDH nanohybrids are proposed to confirm the interlayer structure of drug molecules between LDH layers. ${ }^{42,43,73)}$ Recently, Kang et al. reported a ferulic acid (FA) intercalated $\mathrm{LDH}$ nanohybrid with sustained release property. They proposed two possible interlayer structural models of FA on the basis of XRD and FT-IR analyses and the molecular dimension of FA. In order to confirm the more reliable interlayer structure of FA in (a)

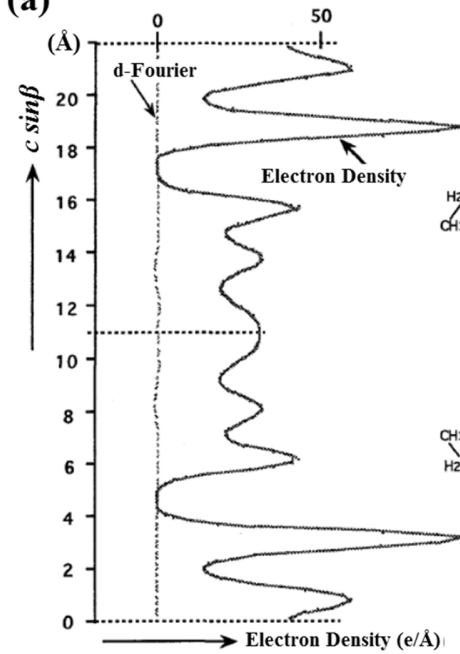

(b)

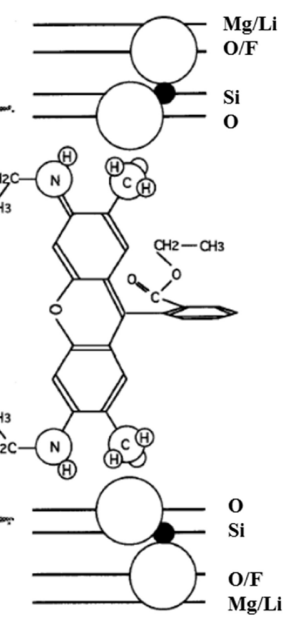

\begin{tabular}{ll}
\hline Position $(\AA)$ & Atoms \\
\hline 0 & $1 \mathrm{Li}, 2 \mathrm{Mg}$ \\
$0.932(7)$ & $2 \mathrm{~F}$ \\
$1.490(8)$ & $4 \mathrm{O}$ \\
$2.804(6)$ & $4 \mathrm{Si}$ \\
$3.544(9)$ & $6 \mathrm{O}$ \\
\hline $5.74(2)$ & $2.4 \mathrm{H}_{2} \mathrm{O}$ \\
\hline 6.144 & $1.1\left(\mathrm{CH}_{3}, \mathrm{NH}, \mathrm{CH}_{2}\right)$ \\
7.344 & $1.1\left(\mathrm{CH}_{3}, \mathrm{C}, \mathrm{C}\right)$ \\
$8.32(2)$ & $1.1\left(0.5\left(\mathrm{O}, \mathrm{O}-\mathrm{CH}_{2}-\mathrm{CH}_{3}\right)\right)$ \\
8.544 & $1.1(\mathrm{CH}, \mathrm{CH})$ \\
9.744 & $1.1(\mathrm{C}, \mathrm{C}, 0.5 \mathrm{C})$ \\
$10.07(2)$ & $1.1(\mathrm{C}, \mathrm{CH})$ \\
10.944 & $1.1(0.5(\mathrm{O}, \mathrm{C}, \mathrm{C}, \mathrm{CH}))$ \\
\hline &
\end{tabular}

Fig. 5. (a) The orientation of rhodamine 6G (R6G) in clay layers and its 1-D electron density profile along the $z$-direction, and (b) positional parameters of the R6G intercalated clay nanohybrid. From [Fujita et al. (1997, Fig. 8 and Table 4)] (reference 66). Reproduced and modified with kind permission of The Clay Minerals Society, publisher of Clays and Clay Minerals. Copyright 1997 The Clay Minerals Society. 
the LDH layers, they computed the 1-D electron density from the integral intensities of the $(00 l)$ XRD peaks and the proposed structural models shown in Fig. 6; the model-1 was based on the perpendicular packing of FA in a zig-zag manner with alternating phenyl-acrylate $\pi-\pi$ interaction (Fig. 6(a)), whereas the model-2 was made under an assumption of tilted packing (tilting angle $\sim 61^{\circ}$ ) of FA moiety to maximize the $\pi-\pi$ interaction between phenyl groups (Fig. 6(b)). The 1-D electron density profile computed from the observed (00l) XRD peaks was compared with those computed from the two structural models. As shown in Fig. 6, the 1-D electron density profile computed from the observed $(00 l)$ XRD peaks was better fitted with that of the model-1 than that of the model-2, where the reliability factor for the former was 0.10 , while that for the latter was 0.19. This result revealed that FA molecules were intercalated between the LDH layers with a perpendicular zig-zag packing orientation rather than with a tilted orientation of $\pi-\pi$ packing between phenyl rings. This FA-LDH nanohybrid showed a controlled release behavior in a simulated body fluid medium.

For the flurbiprofen-LDH nanohybrid, flurbiprofen (FB), a non-steroidal anti-inflammatory drug, was intercalated into $\mathrm{Zn}_{2} \mathrm{Al}-\mathrm{LDH}$ as a new transdermal drug delivery system, and its 1-D electron density was calculated in order to understand the interlayer arrangement of FB drug molecules between the LDH layers. The integral intensities of six welldeveloped $(00 l)$ peaks were used for Fourier transformation, and the positions of $\mathrm{Zn}, \mathrm{Al}$, and $\mathrm{OH}$ in the $\mathrm{LDH}$ layer were obtained from the crystal structure of $\mathrm{Zn}_{2} \mathrm{Al}-\mathrm{CO}_{3} \mathrm{LDH}$. It was found that the rational structure of interlayer FB molecules was an interdigitated bilayer structure oriented with a tilting angle of $\sim 21^{\circ}$ by comparing the calculated and observed electron density profiles, those which were made on the basis of different interlayer orientation models with a tilting angle of the interdigitated bi-layer ranging from $0^{\circ}$ to $31.6^{\circ}$. A strong peak at the z-parameter of $0 \AA$ in the 1-D electron density map corresponds to $\mathrm{Zn}$ and $\mathrm{Al}$ in the $\mathrm{LDH}$ layer, and six additional peaks with lower electron densities could be attributed to the intercalated FB and water molecules in the interlayer. Another example of a bio/inorganic 2-D nanohybrid was the artesunate (AS), anti-malarial drug, intercalated layered zinc hydroxide (ZBS). ${ }^{43}$ The rational structure of the interlayer AS molecules in the ASZBS nanohybrid was also confirmed by 1-D electron density mapping analysis together with TEM analysis.

Recently, a time-resolved in situ energy dispersive X-ray diffraction (EDXRD) experiment was developed using a synchrotron X-ray device. ${ }^{2674-76)}$ This is a very useful tool for investigating the intercalation mechanism and its kinetics, since the intercalation reactions can be simultaneously traced as soon as the guest species is added to the host suspension. From this time-resolved in situ EDXRD, TaviotGueho et al. clarified the second-stage phenomena (the interstratified structure) during the intercalation of tartrate into $\mathrm{Zn}_{2} \mathrm{Cr}-\mathrm{Cl} \mathrm{LDH}{ }^{26)}$ In addition, Williams et al. demon-
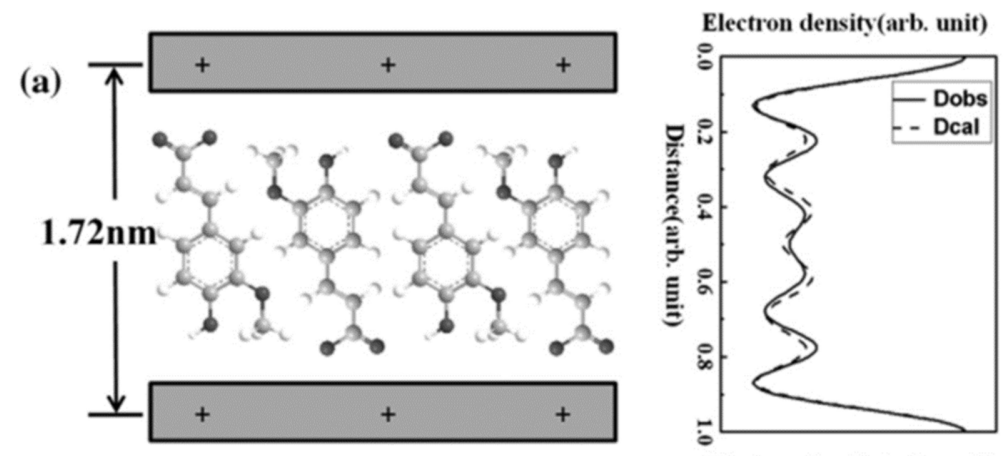

(b)
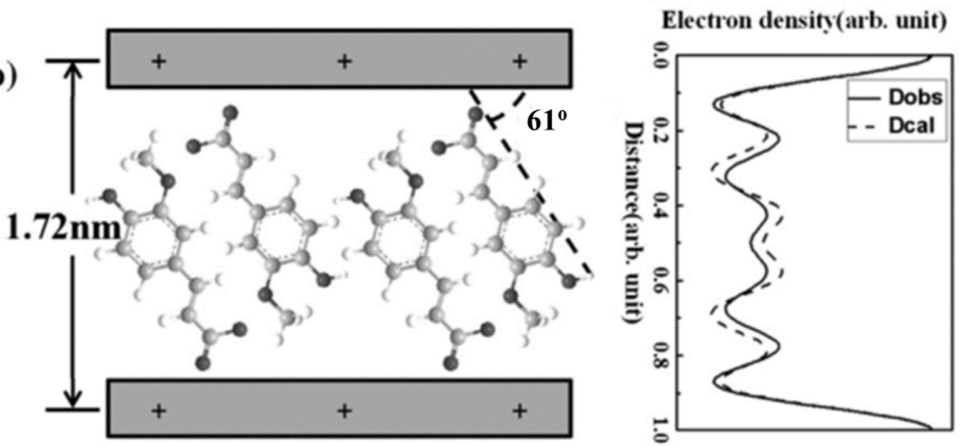

Fig. 6. Two possible interlayer structural models of ferulic acid (FA) intercalated LDH nanohybrid and their corresponding 1-D electron density profiles: (a) Model-1: perpendicular zig-zag packing of FA molecules with an alternating phenol-acrylate $\pi-\pi$ arrangement. (b) Model-2: tilted packing of FA molecules with maximized $\pi-\pi$ interaction between phenyl groups. The solid (Dobs) and dashed (Dcal) lines represent the 1-D electron density profiles from the XRD intensity and structural model, respectively. Reproduced and modified with permission from reference 73. Copyright 2008 Elsevier Ltd. 


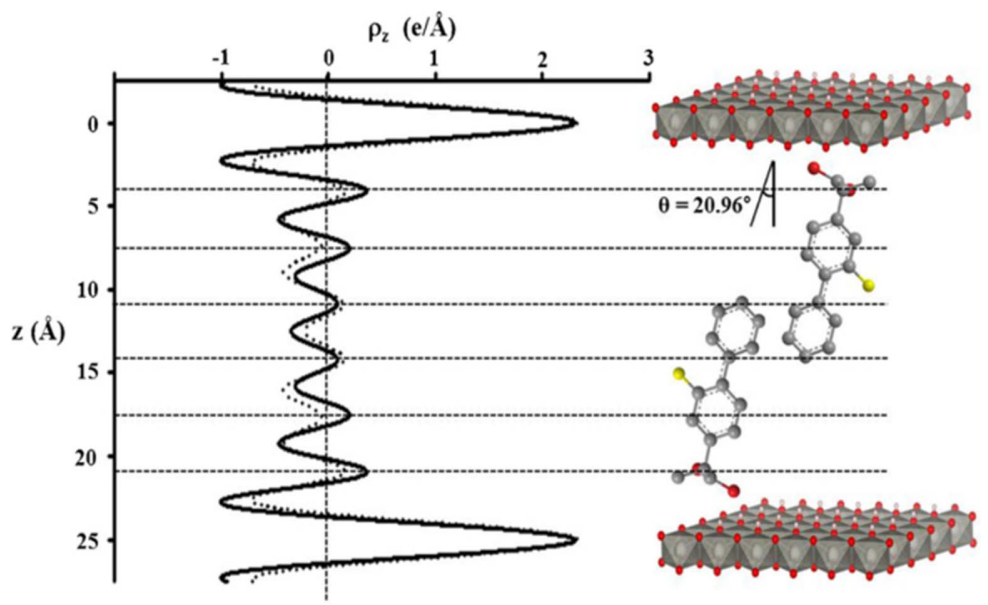

Fig. 7. 1-D electron density profiles along the $z$-direction for flurbiprofen stabilized between the $\mathrm{Zn}_{2} \mathrm{Al}-\mathrm{LDH}$ layers and its corresponding structural model, where the solid and dashed lines indicate the observed and calculated electron density profiles, respectively. Reproduced and modified with permission from the reference 42. Copyright 2013 Elsevier Ltd.

strated the staging structure during phosphonic acid intercalation into $\mathrm{LiAl}_{2}-\mathrm{Cl} \mathrm{LDH}$ via this time-resolved EDXRD analysis. ${ }^{75)}$ This in-situ measurement would be very useful to elucidate the interlayer structures of 2-D nanohybrids together with 1-D electron density mapping analysis.

\section{Summary}

Various types of guest species, such as molecules with cationic charge or anionic one, metal ions, metal oxide clusters, polymers, and even 2D oxide nanosheets have been incorporated into the inter-gallery of layered ceramic materials such as clays, LDHs, graphite, layered metal oxides and layered transition metal chalcogenides to form 2-D nanohybrids with various heterostructures. It is always an important issue to understand the interlayer structure of guest species between host ceramic layers, not only to trace intercalation reactions but also to understand their physicochemical properties in terms of the structure-property relationships. In this regard, the 1-D electron density mapping analysis is very useful tool to elucidate the interlayer structure in 2-D nanohybrids together with x-ray spectroscopy (XANES and EXAFS), NMR and TEM analyses. We hope that some of the highlighted examples in this review will provide useful information to readers who are currently working on new 2-D nanohybrids based on ceramic lamellar materials such as inorganic/ceramic-, organic/ceramic- and bio/ceramic-2D nanohybrids with various heterostructures.

\section{Acknowledgments}

This work was supported by a grant from the National Research Foundation of Korea (NRF) funded by the Korean government (MSIP) (2005-0049412 and NRF-2013R1A1A 2062239).

\section{REFERENCES}

1. J. H. Choy, S. J. Choi, J. M. Oh, and T. Park, "Clay Minerals and Layered Double Hydroxides for Novel Biological Applications," Appl. Clay Sci., 36 [1-3] 122-32 (2007).

2. J. M. Oh, T. T. Biswick, and J. H. Choy, "Layered Nanomaterials for Green Materials," J. Mater. Chem., 19 [17] 255363 (2009).

3. (a) J. Y. Kim, I. Chung, J. H. Choy, and G. S. Park, "Macromolecular Nanoplatelet of Aurivillius-Type Layered Perovskite Oxide, $\mathrm{Bi}_{4} \mathrm{Ti}_{3} \mathrm{O}_{12}$, Chem. Mater., 13 [9] 2759-61 (2001). ; (b) S. M. Paek, H. Jung, Y. J. Lee, M. Park, S. J. Hwang, and J. H. Choy, "Exfoliation and Reassembling Route to Mesoporous Titania Nanohybrids," Chem. Mater., 18 [5] 1134-40 (2006).

4. T. W. Kim, H. W. Ha, M. R. Paek, S. H. Hyun, I. H. Paek, J. H. Choy, and S. J. Hwang, "Mesoporous Iron Oxide-Layered Titanate Nanohybrids: Soft-Chemical Synthesis, Characterization, and Photocatalyst Application," J. Phys. Chem. C, 112 [38] 14853-62 (2008).

5. (a) S. M. Paek, H. Jung, M. Park, J. K. Lee, and J. H. Choy, "An Inorganic Nanohybrid with High Specific Surface Area: $\mathrm{TiO}_{2}$-Pillared $\mathrm{MoS}_{2}$," Chem. Mater., 17 [13] 3492-98 (2005); (b) H. Lim, S. I. Yoon, G. Kim, A. R. Jang, and H. S. Shin, "Stacking of Two-Dimensional Materials in Lateral and Vertical Directions," Chem. Mater., 26 [17] 4891-903 (2014).

6. S. M. Auerbach, K. A. Carrado, and P. K. Dutta, Handbook of Layered Materials; pp. 1-539, CRC Press, New York, 2004.

7. Q. Wang and D. O'Hare, "Recent Advances in the Synthesis and Application of Layered Double Hydroxide (LDH) Nanosheets," Chem. Rev., 112 [7] 4124-55 (2012).

8. D. H. Park, S. J. Hwang, J. M. Oh, J. H. Yang, and J. H. Choy, "Polymer-Inorganic Supramolecular Nanohybrids for Red, White, Green, and Blue Applications," Prog. Polym. Sci., 38 [10-11] 1442-86 (2013).

9. J. H. Choy, S. Y. Kwak, Y. S. Han, and B. W. Kim, "New Organo-Montmorillonite Complexes with Hydrophobic and 
Hydrophilic Functions," Mater. Lett., 33 [3-4] 143-47 (1997).

10. J. H. Choy, "Intercalative Route to Heterostructured Nanohybrid," J. Phys. Chem. Solids, 65 [2-3] 373-83 (2004).

11. M. Ogawa and K. Kuroda, "Photofunctions of Intercalation Compounds," Chem. Rev., 95 [2] 399-438 (1995).

12. M. S. Whittingham, and A. J. Jacobson, Intercalation Chemistry; pp. 1-100, 229-360, 573-89, Academic Press, New York, 1982.

13. D. W. Bruce and D. O'Hare, Inorganic Materials; $2^{\text {nd }}$ Eds, pp. 171-254, 313-76, John Wiley \& Sons Ltd, West Sussex, England, 1997.

14. S. M. Paek, J. M. Oh, and J. H. Choy, "A Lattice-Engineering Route to Heterostructured Functional Nanohybrids," Chem. Asian J., 6 [2] 324-38 (2011).

15. E. R. Hitzky, P. Aranda, M. Darder, and G. Rytwo, "Hybrid Materials Based on Clays for Environmental and Biomedical Applications,", J. Mater. Chem., 20 [42] 9306-21 (2010).

16. (a) J. L. Gunjakar, T. W. Kim, H. N. Kim, I. Y. Kim, and S. J. Hwang, "Mesoporous Layer-by-Layer Ordered Nanohybrids of Layered Double Hydroxide and Layered Metal Oxide: Highly Active Visible Light Photocatalysts with Improved Chemical Stability,” J. Am. Chem. Soc., 133 [38] 14998-5007 (2011); (b) J. L. Gunjakar, I. Y. Kim, J. M. Lee, N. S. Lee, and S. J. Hwang, "Self-Assembly of Layered Double Hydroxide 2d Nanoplates with Graphene Nanosheets: An Effective Way to Improve The Photocatalytic Activity of 2d Nanostructured Materials for Visible Light-Induced $\mathrm{O}_{2}$ Generation," Energy Environ. Sci., 6 [3] 1008-17 (2013).

17. J. M. Oh, D. H. Park, and J. H. Choy, "Integrated Bio-Inorganic Hybrid Systems for Nano-Forensics," Chem. Soc. Rev., 40 [2] 583-95 (2011).

18. V. K. Mudhivarthi, A. Bhambhani, and C. V. Kumar, "Novel Enzyme/DNA/Inorganic Nanomaterials: A New Generation of Biocatalysts," Dalton Trans., [47] 5483-497 (2007).

19. S. R Lee, M. Park, Y. S. Han, S. H. Hwang, and J. H. Choy, "Trivalent Atom Contribution on Solid-Solid Transformation of Ga13 Polycation Intercalated Clay into Sodalite Investigated by X-ray Absorption Spectroscopy," J. Phys. Chem. B, 109 [19] 9432-36 (2005).

20. Z. Zeng, D. Matuschek, A. Studer, C. Schwickert, R. Pöttgen, and H. Eckert, "Synthesis and Characterization of Inorganic-Organic Hybrid Materials Based on the Intercalation of Stable Organic Radicals Into a Fluoromica Clay," Dalton Trans., 42 [24] 8585-96 (2013).

21. A. C. Gomes, S. M. Bruno, C. A. Gamelas, A. A. Valente, M. Abrantes, I. S. Gonçalves, C. C. Romão, and M. Pillinger, "Intercalation of a Molybdenum $n^{3}$-Allyl Dicarbonyl Complex in a Layered Double Hydroxide and Catalytic Performance in Olefin Epoxidation," Dalton Trans., 42 [23] 823140 (2013).

22. S. Arias, J. G. Eon, R. A. S. San Gil, Y. E. Licea, L. A. Palacio, and A. C. Faro Jr., "Synthesis and Characterization of Terephthalate-Intercalated Nial Layered Double Hydroxides with High Al Content," Dalton Trans., 42 [6] 2084-93 (2013).

23. (a) F Bergaya and G. Lagaly, Handbook of Clay Science $2^{\text {nd }}$ Ed. Part A: Fundamentals; pp. 1-81, Elsevier, Amsterdam,
2013; (b) F Bergaya and G. Lagaly, Handbook of Clay Science $2^{\text {nd }}$ Ed. Part B: Techniques and Applications; pp. 1423, Elsevier, Amsterdam, 2013.

24. G. R. Williams and D. O'Hare, "Towards Understanding, Control and Application of Layered Double Hydroxide Chemistry," J. Mater. Chem., 16 [30] 3065-74 (2006).

25. G. R. Williams, A. M. Fogg, J. Sloan, C. Tavio-Guého, and D. O'Hare, "Staging during Anion-Exchange Intercalation into $\left[\mathrm{LiAl}_{2}(\mathrm{OH})_{6}\right] \mathrm{Cl} \mathrm{yH}_{2} \mathrm{O}$ : Structural and Mechanistic Insights," Dalton Trans., [32] 3499-506 (2007).

26. C. Tavio-Guého, Y. Feng, A. Faour, and F. Leroux, "Intercalation Chemistry in a LDH System: Anion Exchange Process and Staging Phenomenon Investigated by Means of Time-Resolved, In Situ X-Ray Diffraction," Dalton Trans., [26] 5994-6005 (2010).

27. D. H. Park, J. H. Yang, A. Vinu, A. Elzatahry, and J. H. Choy, "X-ray Diffraction and X-Ray Absorption Spectroscopic Analyses for Intercalative Nanohybrids with Low Crystallinity," Arab. J. Chem., 9 [2] 190-205 (2016).

28. V. Rives, Layered Double Hydroxides: Present and Future; pp. 2-215, Nova Science Publishers, Inc., New York, 2001.

29. I. Park, Y. S. Han, and J. H. Choy, "Facile Exfoliation of Layered Titanoiobate $\left(\mathrm{KTiNbO}_{5}\right)$ into Colloidal Nanosheets," J. Nanosci. Nanotechnol., 9 [12] 7190-94 (2009).

30. J. H. Choy, S. J. Kwon, and G. S. Park, "High-T $\mathrm{T}_{\mathrm{c}}$ Superconductors in the 2D Limit: $\left[\left(\mathrm{Py}_{-} \mathrm{C}_{\mathrm{n}} \mathrm{H}_{2 \mathrm{n}+1}\right)_{2} \mathrm{HgI}_{4}\right]-\mathrm{Bi}_{2} \mathrm{Sr}_{2} \mathrm{Ca}_{\mathrm{m}-1} \mathrm{Cu}_{\mathrm{m}} \mathrm{O}_{\mathrm{y}}$ ( $\mathrm{m}=1$ and 2)," Science, 280 [5369] 1589-92 (1998).

31. J. H. Choy, Y. I. Kim, and S. J. Hwang, "Superionic and Superconducting Nanohybrids with Hetero-Structure, $\mathrm{Ag}_{\mathrm{x}} \mathrm{I}_{\mathrm{w}}$ $\mathrm{Bi}_{2} \mathrm{Sr}_{2} \mathrm{Ca}_{\mathrm{n}-1} \mathrm{Cu}_{\mathrm{n}} \mathrm{O}_{\mathrm{y}}(0.76 £ \mathrm{x} £ 1.17 ; \mathrm{n}=1,2$, and 3), J. Phys. Chem. B, 102 [46] 9191-202 (1998).

32. T. Sasaki and M. Watanabe, "Osmotic Swelling to Exfoliation. Exceptionally High Degrees of Hydration of a Layered Titanate," J. Am. Chem. Soc., 120 [19] 4682-89 (1998).

33. R. Ma and T. Sasaki, "Nanosheets of Oxides and Hydroxides: Ultimate 2D Charge-Bearing Functional Crystallites," Adv. Mater., 22 [45] 5082-104 (2010).

34. J. L. Gunjakar, I. Y. Kim, J. M. Lee, Y. K. Jo, and S. J. Hwang, "Exploration of Nanostructured Functional Materials Based on Hybridization of Inorganic 2D Nanosheets," J. Phys. Chem. C, 118 [8] 3847-63 (2014).

35. S. J. Kim, S. Lemaux, G. Demazeau, J. Y. Kim, and J. H. Choy, "LaPdO ${ }_{3}$ : the First $\mathrm{Pd}^{\mathrm{III}}$ Oxide with the Perovskite Structure," J. Am. Chem. Soc., 123 [42] 10413-14 (2001).

36. J. H. Choy, S. T. Hong, and K. S. Choi, "Crystal Structure, Magnetism and Phase Transformation in Perovskites $\mathrm{A}_{2} \mathrm{CrNbO}_{6}(\mathrm{~A}=\mathrm{Ca}, \mathrm{Sr}, \mathrm{Ba}), "$ J. Chem. Soc. Faraday Trans., 92 [6] 1051-59 (1996).

37. J. H. Choy, J. Y. Kim, S. J. Kim, J. S. Sohn, and O. H. Han, "New Dion-Jacobson-Type Layered Perovskite Oxyfluorides, $\mathrm{ASrNb}_{2} \mathrm{O}_{6} \mathrm{~F}(\mathrm{~A}=\mathrm{Li}, \mathrm{Na}$, and $\mathrm{Rb}), "$ Chem. Mater., 13 [3] 906-12 (2001).

38. R. A. Young, The Rietveld Method; pp. 1-298, Oxford University Press, Oxford, 1993.

39. J. H. Yang, Y. S. Han, M. Park, T. Park, S. J. Hwang, and J. H. Choy, "New Inorganic-Based Drug Delivery System of Indole-3-Acetic Acid-Layered Metal Hydroxide Nanohybrids with Controlled Release Rate," Chem. Mater., 19 [10] 2679-85 (2007). 
40. (a) H. Jung, H. M. Kim, Y. B. Choy, S. J. Hwang, and J. H. Choy, "Itraconazole-Laponite: Kinetics and Mechanism of Drug Release," Appl. Clay Sci., 40 [1-4] 99-107 (2008); (b) J. H. Yang, H. Jung, S. Y. Kim, and J. H. Choy, "Heterostructured Layered Aluminosilicate-Itraconazole Nanohybrid for Drug Delivery System,” J. Nanosci. Nanotechnol., 13 7331-36 (2013).

41. J. H. Yang, H. Piao, A. Vinu, A. A. Elzatahry, S. M. Paek, and J. H. Choy, " $\mathrm{TiO}_{2}$-Pillared Clays with Well-Ordered Porous Structure and Excellent Photocatalytic Activity," RSC Adv., 5 [11] 8210-15 (2015).

42. M. H. Kim, D. H. Park, J. H. Yang, Y. B. Choy, and J. H. Choy, "Drug-Inorganic-Polymer Nanohybrid for Transdermal Delivery," Int. J. Pharm, 444 [1-2] 120-27 (2013).

43. J. Y. Kim, J. H. Yang, J. H. Lee, G. Choi, D. H. Park, M. R. Jo, S. J. Choi, and J. H. Choy, "2D Inorganic-Antimalarial Drug-Polymer Hybrid with pH Responsive Solubility," Chem. Asian J., 10 [10] 2264-71 (2015).

44. J. G. Thompson and C. Cuff, "Crystal Structure of Kaolinite: Dimethylsulfoxide Intercalate," Clays Clay Miner., 33 [6] 490-500 (1985).

45. F. Thevenot, R. Szymanski, and P. Chaumette, "Preparation and Characterization of Al-Rich Zn-Al HydrotalciteLike Compounds," Clays Clay Miner., 37 [5] 396-402 (1989).

46. U. Costantino, F. Marmottini, M. Nocchetti, and R. Vivani, "New Synthetic Routes to Hydrotalcite-Like Compounds Characterisation and Properties of the Obtained Materials," Eur. J. Inorg. Chem., 1998 [10] 1439-46 (1998).

47. A. Ennadi, A. Legrouri, A. D. Roy, and J. P. Besse, "X-Ray Diffraction Pattern Simulation for Thermally Treated [ZnAl-Cl] Layered Double HydroxideX-Ray Diffraction Pattern Simulation for Thermally Treated [Zn-Al-Cl] Layered Double HydroxideX-Ray Diffraction Pattern Simulation for Thermally Treated [Zn-Al-Cl] Layered Double Hydroxide," J. Solid State Chem., 152 [2] 568-72 (2000).

48. J. H. Choy, S. J. Hwang, and N. G. Park, "Intracrystalline Structure of Molecular Mercury Halide Intercalated in High- $\mathrm{T}_{\mathrm{c}}$ Superconducting Lattice of $\mathrm{Bi}_{2} \mathrm{Sr}_{2} \mathrm{CaCu}_{2} \mathrm{O}_{\mathrm{y}}$, , J. Am. Chem. Soc., 119 [7] 1624-33 (1997).

49. W. K. Kuks and Y. D. Huh, "Preferential Intercalation of Isomers of Anthraquinone Sulfonate Ions into Layered Double Hydroxides," J. Mater. Chem., 7 [9] 1933-36 (1997).

50. A. V. Besserguenev, A. M. Fogg, R. J. Francis, S. J. Price, and D. O'Hare, "Synthesis and Structure of the Gibbsite Intercalation Compounds $\left[\mathrm{LiAl}_{2}(\mathrm{OH})_{6}\right] \mathrm{X}\left\{\mathrm{X}=\mathrm{Cl}, \mathrm{Br}, \mathrm{NO}_{3}\right\}$ and $\left[\mathrm{LiAl}_{2}(\mathrm{OH})_{6}\right] \mathrm{Cl} \cdot \mathrm{H}_{2} \mathrm{O}$ Using Synchrotron X-ray and Neutron Powder Diffraction," Chem. Mater., 9 [1] 241-47 (1997).

51. C. P. Vicente, J. L. Tirado, K. Adouby, J. C. Jumas, A. A. Touré, and G. Kra, "X-ray Diffraction and ${ }^{119} \mathrm{Sn}$ Mössbauer Spectroscopy Study of a New Phase in the $\mathrm{Bi}_{2} \mathrm{Se}_{3}-\mathrm{SnSe}$ System: $\mathrm{SnBi}_{4} \mathrm{Se}_{7}$," Inorg. Chem., 38 [9] 2131-35 (1999).

52. P. Lavela, J. Morales, and J. L. Tirado, "Sodium Intercalation into $(\mathrm{PbS})_{1.18}\left(\mathrm{TiS}_{2}\right)_{2}$ Misfit Layer CompoundSodium Intercalation into $(\mathrm{PbS})_{1.18}\left(\mathrm{TiS}_{2}\right)_{2}$ Misfit Layer CompoundSodium Intercalation into $(\mathrm{PbS})_{1.18}\left(\mathrm{TiS}_{2}\right)_{2}$ Misfit Layer CompoundSodium Intercalation into $(\mathrm{PbS})_{1.18}\left(\mathrm{TiS}_{2}\right)_{2}$ Misfit Layer Compound," J. Solid State Chem., 124 [2] 238-43
(1996).

53. F. Leroux and C. Taviot-Guého, "Fine Tuning between Organic and Inorganic Host Structure: New Trends in Layered Double Hydroxide Hybrid Assemblies," J. Mater. Chem., 15 [35-36] 3628-42 (2005).

54. T. Itoh, T. Shichi, H. Takahashi, Y. Inui, and K. Takagi, "Reversible Color Changes in Lamella Hybrids of Poly(diacetylenecarboxylates) Incorporated in Layered Double Hydroxide Nanosheets," J. Phys. Chem. B, 109 [8] 3199-206 (2005).

55. Y.-J. Liu, J. L. Schindler, D. C. DeGroot, C. R. Kannewurf, W. Hirpo, and M. G. Kanatzidis, "Synthesis, Structure, and Reactions of Poly(ethylene oxide) $/ \mathrm{V}_{2} \mathrm{O}_{5}$ Intercalative Nanocomposites," Chem. Mater., 8 [2] 525-34 (1996).

56. C. H. L. Kennard, "Practical Experiments in Crystallography. Structure Solution Using 'Patterson' Heavy-Atom Technique,” J. Appl. Cryst., 5382 (1972).

57. P. Delatorre and W. F. de Azevedo Jr, "Simulation of Electron Density Ma3ps for Two-Dimensional Crystal Structures Using Mathematica," J. Appl. Cryst., 34 658-60 (2001).

58. M. F. C. Land and R. A. Palmer, Structure Determination by X-ray crystallography $3^{\text {rd }} \mathrm{Ed}$; pp. 117-365, Plenum Press, New York, 1994.

59. A. J. C. Wilson, E. Prince, International Tables for Crystallography, Vol. C, $2^{\text {nd }}$ edition, pp. 554-89, Kluwer Academic Publishers, Boston/Dordrecht/London, 1999.

60. Z. W. Su and P. pp. 554-589, Coppens, "Relativistic X-ray Elastic Scattering Factors for Neutral Atoms Z = 1-54 from Multiconfiguration Dirac-Fock Wavefunctions in the 0$12 \AA^{-1} \sin \theta / 1$ Range, and Six-Gaussian Analytical Expressions in the 0-6 $\AA^{-1}$ Range," Acta. Cryst., A53 749-62 (1997).

61. V. K. Pecharsky and P. Y. Zavalij, Fundamentals of Powder Diffraction and Structural Characterization of Materials; pp.1-346, Springer, New York, 2005.

62. M. Uehara, A. Yamazaki, T. Umezawa, K. Takahashi, and S. Tsutsumi, "A Nickel Hydroxide-Vermiculite Complex: Preparation and Characterization," Clays Clay Miner., 47 [6] 726-31 (1999).

63. J. H. Choy, Y. I. Kim, S. J. Hwang, Y. Muraoka, N. Ohnishi, K. Hiraga, and P. V. Huong, "HRTEM and MicroRaman Studies on Superconducting-Superionic Conducting Nanohybrid, $\mathrm{Ag}_{1.17} \mathrm{I}_{1.54} \mathrm{Bi}_{2} \mathrm{Sr}_{2} \mathrm{CaCu}_{2} \mathrm{O}_{\mathrm{y}}$," J. Phys. Chem. B, 104 [39] 9086-90 (2000)

64. A. Argüelles, M. Leoni, J. A. Blanco, and C. Marcos, "SemiOrdered Crystalline Structure of the Santa Olalla Vermiculite Inferred from X-ray Powder Diffraction," Am. Mineral., 95 [1] 126-34 (2010).

65. R. Marangoni, C. Taviot-Guého C, A. Illaik, F. Wypych, and F. Leroux, "Organic Inorganic Dye Filler for Polymer: Blue-Coloured Layered Double Hydroxides into Polystyrene," J. Colloid Interface Sci., 326 [2] 366-73 (2008).

66. T. Fujita, N. Iyi, T. Kosugi, A. Ando, T. Deguchi, and T. Sota, "Intercalation Characteristics of Rhodamine 6G in Fluor-Taeniolite: Orientation in the Gallery," Clays Clay Miner., 45 [1] 77-84 (1997).

67. J. M. Adams, J. M. Thomas, and M. J. Walters, "Surface and Intercalate Chemistry of the Layered Silicates. Part VI. Tetrahydrofuran Intercalates of a Series of Cation- 
Exchanged Montmorillonites," J. Chem. Soc. Dalton, [2] 112-15 (1976).

68. J. M. Adams, "Surface and Intercalate Chemistry of Layered Silicates. Part III. X-Ray Investigation of Tetrahydropyran and 1,4-Dioxan Intercalates of Montmorillonite," $J$. Chem. Soc. Dalton, [20] 2286-88 (1974).

69. J. Rodriguez-Carvajal, Fullprof Computer Program, https:// www.ill.eu/?id=2527. Accessed on 29/06/2016.

70. J. Bauer, P. Behrens, M. Speckbacher, and H. Langhals, "Composites of Perylene Chromophores and Layered Double Hydroxides: Direct Synthesis, Characterization, and Photo- and Chemical Stability," Adv. Funct. Mater., 13 [3] 241-48 (2003).

71. W. Katinonkul and M. M. Lerner, "The First Synthesis of a Graphite Bis(Oxalato)Borate Intercalation Compound," $J$. Phys. Chem. Solids, 68 [3] 394-99 (2007).

72. E. Káfuňková, K. Lang, P. Kubát, M. Klementová, J. Mosinger, M. Šlouf, A. L. Troutier-Thuilliez, F. Leroux, V. Verney, and C. Taviot-Guého, "Porphyrin-Layered Double Hydroxide/Polymer Composites as Novel Ecological Photo- active Surfaces," J. Mater. Chem., 20 [42] 9423-32 (2010).

73. H. Kang, H. J. Kim, J. H. Yang, T. H. Kim, G. Choi, S. M. Paek, A. J. Choi, J. H. Choy, and J. M. Oh, "Intracrystalline Structure and Release Pattern of Ferulic Acid Intercalated into Layered Double Hydroxide through Various Synthesis Routes," Appl. Clay Sci., 112-113 32-9 (2015).

74. A. M. Fogg, J. S. Dunn, and D. O'Hare, "Formation of Second-Stage Intermediates in Anion-Exchange Intercalation Reactions of the Layered Double Hydroxide $\left[\mathrm{LiAl}_{2}(\mathrm{OH})_{6}\right]$ $\mathrm{Cl} \cdot \mathrm{H}_{2} \mathrm{O}$ As Observed by Time-Resolved, in Situ X-ray Diffraction," Chem. Mater., 10 [1] 356-60 (1998).

75. G. R. Williams, A. J. Norquist, and D. O'Hare, "TimeResolved, In Situ X-ray Diffraction Studies of Staging during Phosphonic Acid Intercalation into $\left[\mathrm{LiAl}_{2}(\mathrm{OH})_{6}\right] \mathrm{Cl}$. $\mathrm{H}_{2} \mathrm{O}$," Chem. Mater., 16 [6] 975-81 (2004).

76. K. Simmance, W. van Beek, and G. Sankar, "Time Resolved In Situ X-Ray Diffraction Study of Crystallisation Processes of Large Pore Nanoporous Aluminophosphate Materials," Faraday Discuss., 177 237-47 (2015). 